\title{
Production and Marketing Constraints of Cotton Under Smallholders: The Case of Arbaminch Zuria District, Southern Ethiopia
}

\author{
Getinet Belay* \\ Ethiopian Institute of Agricultural Research, Werer Agricultural Research Center \\ PO box, 2003, Addis Ababa, Ethiopia \\ Arkebe G/egziabher \\ Ethiopian Institute of Agricultural Research, Werer Agricultural Research Center \\ PO box, 2003, Addis Ababa, Ethiopia \\ Rehima Mussema \\ Ethiopian Institute of Agricultural Research (EIAR), Addis Ababa \\ PO box, 2003, Addis Ababa, Ethiopia
}

\begin{abstract}
The study focused on the analysis of production and marketing constraints of cotton among rural farmers in Arbaminch Zuria district of Southern Region of Ethiopia. A total of 68 respondents were interviewed using questionnaire. Data was analyzed using descriptive statistics to describe the socio-economic characteristics of the farmers and to identify major production and marketing constraints. The main production constraints noticed were inadequate knowledge of recommended packages and practices, non-availability of improved seed both in quality and quantity, lack of technical knowledge regarding the crop and insects, pests and disease attack. The main marketing constraints that hampered smallholder cotton producers were non-availability of reliable market information, price fluctuation, involvement of large number of intermediaries/ brokers in marketing, smallness of quantity to be sold, product absence of cooperatives among producers and lack of value addition in the seedcotton product. Given the high local demand for cotton and the potential for expansion, it is important to address these challenges for producers to benefit from market opportunities and increase their income. However, dealing with these challenges will require a whole value chain approach.
\end{abstract}

Keywords: Cotton, Production, Marketing, Constraints, Smallholder producers, Arbaminch Zuria

DOI: $10.7176 / \mathrm{JMCR} / 67-01$

Publication date: April $30^{\text {th }} 2020$

\section{Introduction}

Cotton is one of the rare agricultural products where both production and consumption is more or less global in extent. It is an important sector for many countries and in developing countries; it contributes for poverty reduction and is an important engine for growth. Currently, it is produced in over 100 countries to meet the domestic needs of fiber and textile industry and as an international trading commodity. The bulk of production takes place in countries like China, United States, India, Pakistan and Brazil. Nevertheless, many low-income countries in Sub-Saharan Africa and elsewhere depend heavily on cotton for earning foreign exchange (Anderson and Valenzuela, 2006).

Cotton, over the years considered as white gold, has acquired an immanent position in Ethiopian agriculture because it is bestowed with some special characteristics. It is one of the oldest cultivated and the major cash crops in the country offering considerable employment opportunities in agriculture and related processing and textile sub-sectors. Cotton gained much significance because it served the dual purpose of providing raw materials to the growing textile industry/agro-industry as well as introducing cash to the economy and livelihoods of millions of people. According to the information obtained from Ethiopian Cotton Producers, Ginners and Exporters Association (CPGEA, 2016), 65 percent of the cotton that are locally produced come from large enterprises (public \& private), while the remaining 35 percent of the cotton come from smallholder farmers. Moreover, about $85 \%$ rural population meets a significant part of its clothing needs from traditional non-formal cotton industrial sector (Kiya, A et al., 2016).

Cotton is widely cultivated in Ethiopia both under irrigated and rainfed conditions by large-scale commercial farms and small-scale farmers at many areas having warm environment with an elevation ranges from 300-1800 meters above sea level. The country has some 3,000,810 hectares of land identified as suitable for cotton production (MoA, 2011). However, in spite of high potential area, the current production is negligible proportion of that and dwindles downwards.

The current seedcotton production level of the country still explain neither the cotton sub-sector's potential nor 
the satisfying of domestic-industry's demand and yield obtained per hectare in Ethiopia is far less than the other countries averaging about $759 \mathrm{kgha}^{-1}$ (FAO, 2016). SOFERCO (2016), report indicated that the current cotton productivity in Ethiopia is estimated to be 2.0-3.0 ton/ha (irrigated) and 1.2-1.7 ton/ha (rain-fed). According to the estimate, despite the potential, the productivity of cotton in Ethiopia is very poor/low.

On the other hand, the textile, garments and apparel sector in the country is growing at much faster pace than cotton production. The increased demand created for cotton due to proliferation of textile and garmentmanufacturing companies apart from the local handlooms necessitated the purchase and importation of considerable amount of lint cotton from abroad, which experts believe widen in the future, to the extent that the nation would become a net importer of lint cotton. Thus, Ethiopia should accelerate towards increased production and productivity of cotton to benefit from the ever-increasing local and foreign markets. To achieve these benefits, factors responsible for low productivity of the cotton sector in the country under large-scale commercial and smallholder production systems as well as the combined bottleneck of marketing systems of the sub-sectors need to be identified and documented in detail and solutions have to be suggested.

As elsewhere in the country, producers of cotton in the Southern Nation Nationalities and Peoples Region (SNNPR) generally and in Arbaminch zuria district in particular have also faced with a number of production and marketing challenges causing many of them to refrain from cotton production. Even though limited studies have done on cotton production and marketing aspects, most of these studies were concentrated on specific areas (Bosena T. et al., 2011; Bosena T. 2008; EIA, 2012) and little is known about production and marketing constraints and challenges of cotton under smallholder production condition. As of these studies, there is wide gap between the potential yield of seedcotton and yield actually obtained in the field in Ethiopia. Cotton marketing constraints identified by RATES (Agridev Consult., 2004) are inadequate knowledge about market standard, lack of market information, absence of a system for contractual production and marketing arrangements, inadequacy of support through service cooperatives and lack of finance. However, the finding was entirely based on secondary data and rapid appraisal methods. Cotton marketing constraints in the chain were not identified in detail through formal survey.

The above views show the importance of production as well as marketing systems of cotton. The development of market and marketing system is next important as that of increasing productivity. The trend in modern agriculture is increasing the scope of agricultural marketing from the point of view of product marketing with fair remuneration in agricultural production. This study, therefore, attempted to contribute its part in filling the information gap by assessing the production and marketing constraints and opportunities of cotton under smallholder production system in Arbaminch Zuria district, SNNPR of Ethiopia.

\section{Research Methodology}

\subsection{Description of the Study Area}

The study was carried out in Arbaminch Zuria district of Southern Ethiopia, situated between $5^{\circ} 42^{\prime}$ to $6^{\circ} 13^{\prime}$ North latitude and $37^{\circ} 19^{\prime}$ to $37^{\circ} 41^{\prime}$ East longitude. The elevation of the study area ranges from 1200 meters above sea level around eastern part to 3000 meter above sea level in northwestern part. The district had total population of 187,811 (CSA, 2012) of whom 93,829 are male and 93,982 are female with population density of 194.1 per kilometer square. The district receives bimodal rainfall of $830.7 \mathrm{~mm}$ per annum, with maximum fall in the months of June, July and August. The mean minimum, mean maximum and average temperatures are 15.1, 29.9 and $22.5^{\circ} \mathrm{C}$, respectively. The area falls in the semi-arid moisture regime where evapotranspiration exceeds precipitation implying that there is a need for irrigation to grow different crops including cotton, maize, banana and others.

\subsection{Sampling Technique and Sample Size}

In the study, three stage-sampling procedures were employed to select sample respondents. In the first stage, Arbaminch Zuria district was chosen purposively as it belongs to the largest cotton zones of the Southern region. In the second stage, kebeles were selected in consultation with district officials and agricultural expertise based on the volume of production and the number of cotton farmers. Finally, sample respondents were selected randomly from the kebeles. Accordingly, a total of 68 households, 50 from Shelle Mella kebele and 18 from Chano Mille kebele, were selected for this study.

\subsection{Data Analysis}

Descriptive statistics consisting of simple percentages, frequencies, and tables were used to examine the demographic and socio- economic characteristics of the cotton farmers. The constraints to production and marketing were also ranked using percentage score in SPSS. 


\section{Results and Discussion}

\subsection{Household characteristics}

\subsubsection{Demographic and Socio-Economic Characteristics of Respondents}

In the study, as the survey results revealed, cotton farming is dominated by male producers $(91 \%)$ while female were only $9 \%$ (Table 1 ). This result suggests that women are excluded from cotton growing due to its capital and labor intensiveness. Similarly, studies done elsewhere in Africa indicated that men dominated cotton farming (Basset, 2010; M. K. Alam et al., 2013; Epiphane et al., 2015).

Additionally, the age composition of household heads of cotton farmers shows that $63.24 \%$ were within the age group of less than or equal to 50 years. While, $36.76 \%$ of the cotton producers were within the age group of above 51 years (Table 1). Meanwhile, the mean age of the household head of cotton farmers was 49.5 years with the minimum of 26 and the maximum of 96 years.

Among the socio-economic characteristic of cotton farmers, family/household size is the most detrimental factor affecting the farming activities in the study area, as family labour is the most commonly used source of work force. Family size comprises all the people living in the same house together. The results of the survey analyses (Table 1) show that the family size of cotton producers in the study area varies between a minimum of one and a maximum of ten members with a mean size of 6.69 families per household. Besides, $21 \%$ of the respondents were having a family size of $1-5$ members while the majority of the household $(79 \%)$ were with family size of 6-10 members. The large family size of the producers implies that how family members are important as a farm labour source in cotton production in the area.

The survey results also showed that $18 \%$ of the cotton farmers in the study area have no access to basic education while $27 \%$ were at least able to read and write. Cotton farmers who have access to primary and secondary school education were $44 \%$ and $12 \%$ respectively. The existing literacy level of the producers has showed the room for further improvement of cotton production and productivity in the study area. Farmers who are better educated are generally more open to innovative ideas and new technologies that promote technical change.

The result of the analysis of farm size (Table 1) had it that the majority (74\%) of cotton farmers in the study area had farm size ranging from 1-8 hectares with a mean farm size of 2.1 ha and a minimum and maximum of 0.5 ha and eight ha respectively. The implication is that the cotton farmers in the study area are smallholders. Table 1: Demographic and socioeconomic characteristics of cotton farmers $(n=68)$

\begin{tabular}{lccc}
\hline \multicolumn{1}{c}{ Variable } & Categories & Frequency & Percentage \\
\hline \multirow{2}{*}{ Gender of the producer } & Male & 62 & 91.2 \\
& Female & 6 & 8.8 \\
\hline \multirow{2}{*}{ Age of the producer } & $<=30$ years & 2 & 2.9 \\
& $31-40$ years & 16 & 23.5 \\
& $41-50$ years & 25 & 36.8 \\
Family size & $>50$ & 25 & 36.8 \\
\hline \multirow{3}{*}{ Level of education } & $<=5$ members & 14 & 20.6 \\
& $6-10$ members & 54 & 79.4 \\
\hline \multirow{2}{*}{ Farmland size } & Illiterate & 12 & 17.6 \\
& Read and write & 18 & 26.5 \\
& Primary education & 30 & 44.1 \\
& Secondary education & 8 & 11.8 \\
\hline & $<=0.5$ ha & 3 & 4.4 \\
Experience in cotton farming & $0.6-1$ ha & 15 & 22.1 \\
& $>1$ ha & 50 & 73.5 \\
\hline
\end{tabular}

Source: Own survey data

Table 1 also indicates the number of years of experience in cotton production. It can be seen that $96 \%$ of the respondents have been in the practice of cotton production for more than 5 years (6-45 years). Only 4\% of the respondents have been in cotton production for less than 5 years (3-5 years). This result implies that cotton production is an age long profession and the majority of farmers have been in the business for long and are therefore familiar with the problems of cotton production in the area.

\subsubsection{Institutional Characteristics of Respondents}

The institutional factors considered include; support from extension services, access to credit, membership in 
farmer's association and access to training. Table 2 depicts the percentage distribution of respondent households according to access of institutional factors.

From the results of the survey data analysis, it came out that the majority of cotton farmers in the study area were deprived of the institutional factors considered. Almost all $(97 \%)$ of respondent cotton farmers have no access to credit and no access to advisory and extension services with regard to cotton farming. Similarly, more than half $(59 \%)$ of the respondents were not member of any farmer's group (cooperatives). Moreover, $87 \%$ of the sampled cotton farmers had reported that they did not attain any training on cotton production practices (Table 2).

Table 2: Distribution of respondents with access of institutional factors $(n=68)$

\begin{tabular}{lccc}
\hline \multicolumn{1}{c}{ Descriptive } & Response & Frequency & Percentage \\
\hline Do you have access to cotton extension services? & Yes & 2 & 2.94 \\
& No & 66 & 97.1 \\
\hline Do you have access to credit service for cotton farming? & Yes & 2 & 2.9 \\
& No & 66 & 97.1 \\
\hline Are you a member of any farmer's association? & Yes & 28 & 41.2 \\
& No & 40 & 58.8 \\
\hline Did you attain any training on cotton production practices? & Yes & 9 & 13.2 \\
& No & 59 & 86.8 \\
\hline
\end{tabular}

Source: Own survey data

The overall low or inadequate accesses of institutional factors are therefore hindering the production and productivity of cotton. Since cotton farming is both capital, knowledge and labour intensive, availability of credit and skill are crucial. The implication of these findings is the need for increased availability and quality of extension services for cotton farmers.

\subsection{Production Constraints}

The major production constraints faced by most of the cotton farmers were identified and presented in Table 3 . Accordingly, lack of recommended packages and practices of the crop seemed to be the most pressing constraint limiting cotton production in the study area as reported by all of the sample respondents (100\%). Nonavailability of improved variety seed was reported by $83 \%$ of the cotton growers as the second important production constraints that limit cotton production in the study area.

Table 3: Major production constraints expressed by sample respondents

\begin{tabular}{lcc}
\hline Constraints & Percentage & Rank \\
\hline Lack of technical knowledge & 79.03 & $3^{\text {rd }}$ \\
Lack of recommended packages and practices & 100.00 & $1^{\text {st }}$ \\
Shortage of improved variety seed & 82.58 & $2^{\text {nd }}$ \\
Lack of farming equipment & 52.62 & $5^{\text {th }}$ \\
Non-availability of credit & 44.17 & $6^{\text {th }}$ \\
Insects, pests and diseases & 65.08 & $4^{\text {th }}$ \\
\hline
\end{tabular}

Source: Own survey data

Lack of technical knowledge technology was the third largest constraint limiting cotton production as indicated by $79 \%$ of sample cotton growers. The use of traditional technologies is widespread and continues to constrain this sector. Although farmers have a background in cotton production, they still use traditional crop management practices and are not familiar with modern farming methods. There is no extension service to assist farmers to improve their technical skills as well as disseminate market information with regard to cotton. Insects, pests and disease attacks were mentioned by $65 \%$ of the respondent cotton farmers as the other cotton production constraints in the study area (Table 3).

\subsection{Marketing Constraints}

Under the major constraints pertaining to marketing of seedcotton, lack of market information was the most important problem reported by $92 \%$ of cotton growers (Table 4). Lack of market information was often quoted as a major reason why farmers are not realizing better prices for their produce. There is no extension service nor market information system to arm farmers with knowledge of prices and potential markets. Often, their main source of price information apart from the buyers are other farmers or friends who have just returned from the market that day. Moreover, farmers have very little or no power of arbitrage in the market and have limited choice as to which markets, they can sell into. Consequently, as previously mentioned, they often receive whatever price they are offered. 
Table 4: Major marketing constraints identified

\begin{tabular}{lcc}
\hline \multicolumn{1}{c}{ Constraints } & Percentage & Rank \\
\hline Price fluctuation/ uncertain prices & 85.29 & $2^{\text {nd }}$ \\
Lack of market information & 92.18 & $1^{\text {st }}$ \\
Smallness of quantity to be sold & 44.12 & $4^{\text {th }}$ \\
Lack of proper harvesting and storage facilities & 25.00 & $6^{\text {th }}$ \\
Lack of cooperation among farmers & 35.29 & $5^{\text {th }}$ \\
Existence of large number of intermediaries in the market & 63.24 & $3^{\text {rd }}$ \\
\hline
\end{tabular}

Source: Own survey data

The second most important marketing constraint reported by $85 \%$ the cotton growers was price fluctuation/uncertain prices of seedcotton. The third major constraint reported by $63 \%$ of the sampled respondents was involvement of large number of intermediaries in the marketing, which resulted in decrease of farmers' share.

\section{Conclusion and Recommendations}

Based on the findings of the study the following conclusion and recommendations were made: cotton farmers in the study area have diverse demographic, socioeconomic and institutional characteristics. From the demographic and socioeconomic characteristics of the sampled respondents, it clearly appears that men headed households, majority within active age group of less than 50 years, educated (basic to secondary school) with average land holding of less than three hectares dominate cotton farming in the study area. The study also showed that cotton farming is an age long profession of farmers in the study area. Institutionally, cotton farmers were found to be deprived of credit, extension and training services.

Lack of recommended packages and practices, shortage of improved cotton variety and lack of technical knowledge were the major production constraints faced with cotton producers with their respective order of importance in the study area. Similarly, lack of market information, price risk and large number of intermediaries were the most important marketing constraints identified by producers.

Therefore, the following suggestions and recommendations were forwarded to improve the production and marketing performance of cotton in the district: -

$>$ The existence of long tradition of cotton farming in the study area should be taken as a good opportunity of cotton production because it takes no time and energy to promote new varieties and agronomic practices.

$>$ It is essential to strengthen the linkage between extension agent and farmers to provide technical assistance and guidance to the smallholder cotton growers about the use of recommended practices and production techniques through training and extension services.

$>$ There is a need to timely avail of improved inputs like improved seeds, fertilizers, chemicals and adequate credit facility to cotton farmers at village level.

$>$ Organizing cotton farmers in groups would enhance their reachability in terms of extension services and inputs and their access to markets.

$>$ Focus should be made on providing the market information like prices, arrivals etc. to the farmers.

Finally, further research based on a larger sample size and covering all the main cotton growing districts and use of time series analysis should be considered to strengthen the policy recommendations made.

\section{References}

Agridev Consult. (2004). Cotton-Textile-Apparel Value Chain Report for Ethiopia. Regional Agricultural Trade Expansion Support Program (The RATES Center). Nairobi, Kenya.

Anderson, K. and Valenzuela. E. (2006). The world trade organization's Doha Cotton Initiative: A tale of two issues. World Bank Policy Research Working Paper 3918. May 2006. Washington, DC. [http://www.Spring.erlink.com/ content/g2w830035p88162p.pdf].

Bassett T. (2010). Slim Pickings. Fair trade cotton in West Africa. Geoforum 41:1.

Bosena Tegegne, Bekabil Fufa, Berhanu G/Medhin, and Dirk H. (2011). Factors Affecting Cotton Supply at the Farm Level in Metema District of Ethiopia. Journal Agricultural Biotechnology Ecol, 4:41-51.

Bosena Tegegne. (2008). Cotton Market Chain Analysis: The Case of Metema Woreda, North Gondar Zone, Amhara National Regional State. MSc Thesis, Haramaya University, Haramaya, Ethiopia, 2008.

CPEGA (Cotton Producers Exporters and Ginneries Association). (2016). Ethiopia's Cotton Production, Productivity and Ginneries Sector's Key Challenges and Interventions

CSA (Central Statistical Agency). (2012). Population and Housing Census Report. Addis Ababa, Ethiopia.

EIA (Ethiopian Investment Agency). (2012). Investment Opportunity Profile for Cotton Production and Ginning in Ethiopia. Addis Ababa, Ethiopia. 
Epiphane S., Laurent C., Gian N., Silvere T., and Jonas H. (2015). Socioeconomic Determinants of Organic Cotton Adoption in Benin, West Africa. Journal of Agricultural and Food Economics, 3; 12.

Kiya Adare Tadesse and Sharma, P. D. (2016). Characterization of soils of cotton growing areas of Arbaminch Zuria Woreda, Gamo Gofa zone, Southern Ethiopia. International journal of current Research. 8 (10). 40118-40123.

M. K. Alam, E. Aboki, E.H. Gidado and D. D. Buba. (2013). Economic Analysis of Cotton Production in Selected Local Government Areas of Taraba State, Nigeria. Journal of Agricultural Science, 4(1): 27-31.

MoA (Ministry of Agriculture). (2011). Market Oriented Development Master Plan for Cotton in Ethiopia. Addis Ababa, Ethiopia.

SOFRCO. (2016). National Cotton Development Strategy-Ethiopia (2015-2030). Federal Democratic Republic of Ethiopia. Draft Scoping Study. June 2016. Addis Ababa, Ethiopia. 